\title{
Coronary microcirculation dysfunction in patients with arterial hypertension
}

\author{
Adam Kern ${ }^{1,2}$, Jerzy Górny ${ }^{2}$, Martyna Zaleska ${ }^{3}, 0$ lga Możeńska ${ }^{4,5}$, Jacek Bil ${ }^{6}$ \\ 'Department of Cardiology and Cardiac Surgery, University of Warmia and Mazury, Olsztyn \\ ${ }^{2}$ Department of Cardiology, Provincial Specialist Hospital, Olsztyn \\ ${ }^{3}$ I Department of Cardiology, Warsaw Medical University, Warsaw \\ ${ }^{4}$ Department of Cardiology and Arterial Hypertension, Central Clinical Hospital of the Ministry of Interior and Administration, Warsaw \\ ${ }^{5}$ Department of Internal Medicine, Hypertension and Angiology, Warsaw Medical University, Warsaw \\ ${ }^{6}$ Department of Invasive Cardiology, Centre of Postgraduate Medical Education, Central Clinical Hospital of the Ministry of Interior \\ and Administration, Warsaw
}

\begin{abstract}
The number of articles regarding microcirculation dysfunction in the literature increases. One should bear them in mind especially in case of patients, who declare typical angina, and in whom during coronary angiography we do not reveal significant lesions in coronary arteries. Arterial hypertension is one of diseases, which may contribute to microcirculation dysfunction and vessels remodeling. In this short review, we discuss possible mechanism of abovementioned disturbances.
\end{abstract}

Key words: coronary microcirculation dysfunction; remodeling; arterial hypertension

Arterial Hypertens. 2018, vol. 22, no. 4, pages: 151-155

DOI: 10.5603/AH.a2018.0003

\section{Introduction}

In 2010, arterial hypertension (HTN) was diagnosed in almost $1 / 3$ of the adult population in the world. It is believed that this is the most common cause of premature deaths that can be prevented [1, 2]. The heart is one of organs that is damaged in the course of HTN. The increase in the afterload caused by the increased peripheral pressure leads, among others, to left ventricular hypertrophy. Initially, this is an adaptive change that allows the heart to maintain the cardiac output when the pressure overload increases. However, long-lasting HTN leads to cardiomyocyte inotropic and lusitropic function impairment, which may lead to left ventricular dysfunction and the development of heart failure [3]. These changes, aimed at adapting to the altered con- ditions, which is the increase in the afterload, lead to the so-called myocardium remodeling [4]. Remodeling is the response of the tissue to mechanical, neurohormonal, inflammatory and oxidative stimuli [5]. It is worth emphasizing that if we accept the occurrence of left ventricular hypertrophy as a categorical variable, we will find in the literature data showing its relationship with a significant increase in the risk of coronary heart disease, heart failure (especially with preserved systolic function), stroke, arrhythmia and sudden death [6]. In addition, recently in the literature the issue of the association between coronary microcirculation and remodeling with myocardial infarction in patients who have no lesions or have insignificant lesions in epicardial arteries is frequently raised [7]. In this review, we

Address for correspondence: Adam Kern, MD, PhD

Żołnierska Street 18, 10-561 Olsztyn, Poland

e-mail: adamkern@wp.pl

VM Copyright $@ 2018$ Via Medica, ISSN 2449-6170 
would like to present the current state of knowledge on coronary microcirculation disorders occurring in the group of patients with HTN, their possible etiology and potential consequences.

\section{Physiological conditions}

The vessel wall is constantly exposed to tension and shear stress. The pressure acting on the vessel wall causes so-called muscle tension, while the shearing stress causes the vasodilatation associated with the blood flow. It is the shear stress that is one of the factors regulating the expression of genes involved in the production of factors responsible for both vasodilatation (including nitric oxide or prostacyclin), and vasoconstriction (including endothelin 1, angiotensin II) [8-10]. Under physiological conditions, when dealing with the basic vessel wall tension regulated by the adrenergic system, the above-mentioned vasoactive substances regulate the blood flow [7]. It is worth noting, however, that in diseased conditions, when long-lasting changes in pressure or flow are observed, vasoactive substances are partly responsible for remodeling, because they regulate the function of the vessel wall smooth muscles and the extracellular matrix [7]. What is more, in diseases such as HTN, we often observe decrease in vasodilatation dependent on vasodilating substances released from the endothelium. This is due to the limitation of the nitric oxide bioavailability, which may be related to the decrease in the activity of nitric oxide endothelial synthetase, and partly to the direct reduction of the amount of nitric oxide by reactive oxygen species [11-13].

At this point it is worth recalling differences present in the coronary circulation. This vessel bed is filled mainly during diastole, and the flow is regulated by locally produced metabolites, the autonomic system and the structure of vessel bed itself [7]. In addition, it should be also remembered that according to the Poiseuille's law the blood flow through the vessel is directly proportional to the radius of the vessel raised to the fourth power, and therefore even small changes in the diameter of the vessel can cause a significant reduction in the flow [7].

\section{Pathophysiological processes occurring in the coronary microcirculation}

Microcirculation comprises of vessels with internal diameter below 150-200 $\mu \mathrm{m}$. It should be emphasized that the essence of coronary artery disease is different, where we deal mainly with atherosclerotic plaques occurring in large epicardial arteries, and significant dysfunction of coronary microcirculation, where both structural and functional changes occur within the vessel bed [7]. It is believed that changes in the microcirculation caused by HTN can be manifested in two ways:

— as "dilution" of the vascular network — low density of arterioles, capillaries and probably also veins;

— as "remodeling" — changes in the structure of small arteries and arterioles, which lead to the reduction of the vessel's lumen.

Both hyperplasia and hypertrophy as well as the altered smooth muscle cell system cause narrowing of the vessel's lumen by entering of the middle layer of the vessel's wall into its lumen [5]. This results, among others, in reducing the total lumen of the intramural arterioles on the myocardial section [5]. The "dilution" of the vascular network may be due to an insufficient increase in the number of blood vessels during myocardium mass growth. All these changes, together with appearing perivascular fibrosis, result in limiting the coronary reserve in this group of patients [14]. It is also worth noting that in the case of patients with HTN there are different "types" of remodeling, depending on the type of vessels they refer to. In the case of small resistance arteries, eutrophic or hypertrophic remodeling usually occurs, whereas in large arteries we usually encounter hypertrophic remodeling, which leads to reduction in the cross-sectional area of the vessel [15]. Moreover, in the literature there are data on the different course of remodeling of microcirculation in case of coronary vessels (concentric remodeling) than in mesenteric vessels (eccentric remodeling), and therefore it can be concluded that the pattern of changes also depends on the type of the vessel bed [7]. In case of patients with HTN, changes in the microcirculation also depend on the severity of the disease - eutrophic remodeling in case of moderate HTN and hypertrophic remodeling in case of severe type of the disease $[16,17]$. In addition, it is suggested that changes in the microcirculation may occur at an earlier stage of the disease than the changes observed in large vessels. They may occur, among others, in the metabolic syndrome, one of which HTN is an element [7]. It should also be remembered that currently there are no methods allowing for a quantitative assessment of the microcirculation function. The assessment of the coronary flow reserve is proposed as one of the tools allowing to assess microcirculatory dysfunction in patients, in whom during coronary angiography no significant lesions were revealed [18, 19]. 


\section{Nitric oxide}

Nitric oxide synthase is responsible for NO production. This enzyme has many isomers, including endothelial one. Nitric oxide is formed in response to shear stress acting on the vessel wall or activation of receptors by vasoactive molecules, such as acetylcholine or adenosine [7]. Apart from regulating the vascular wall tension, this compound also plays a role in remodeling of the vascular wall by inhibiting the vessel wall smooth muscle proliferation and by regulating the expression of extracellular protein $[20,21]$. Nitric oxide also maintains the elasticity of the vessel wall and prevents it from stiffening [22]. Numaguchi and colleagues in the rat model showed that the pharmacological blockade of nitric oxide synthetase led to the development of HTN with remodeling of coronary microcirculation (including perivascular fibrosis). In addition, these authors suggested that vascular remodeling was associated in that case with limited bioavailability of nitric oxide since pharmacological normalization of arterial blood pressure did not prevent remodeling [23]. Moreover, the deletion of the gene for endothelial nitric oxide synthetase led to an increase in the thickness of the vessel wall [20]. It was also shown that in the population of animals with HTN, asymmetric dimethylarginine - an endogenous nitric oxide inhibitor - was increased, which was also associated with coronary microvascular remodeling [24]. Decreasing the concentration of asymmetric dimethylarginine caused a decrease in remodeling [25]. The bioavailability of nitric oxide can also be limited by increasing the activity of arginase - an enzyme competing with nitric oxide synthetase for a substrate such as arginine. Increased activity of this enzyme is observed, among others, in the case of HTN $[13,26]$.

\section{Reactive oxygen species}

Physiologically, low concentrations of reactive oxygen species are maintained, however, in diseased conditions, their increased production may contribute to endothelial dysfunction and vessel remodeling. Increased concentrations of reactive oxygen species may be caused by both, their increased production and the limitation of their distribution $[27,28]$. These compounds participate in remodeling, which growth factors such as platelet-derived growth factor and transforming growth factor beta are mainly responsible for [29]. Moreover, reactive oxygen species also regulate vascular wall tension, among others, by intensifying the proliferation and migration of smooth muscle in the vascular wall and changes in the composition of the extracellular matrix $[27,30]$.

\section{The renin-angiotensin-aldosterone system}

Angiotensin II is considered to be the main bioactive element of this system. Through various mechanisms it helps to maintain the appropriate blood pressure. One of them is the vasodilator effect by affecting the vessel wall smooth muscles. This protein is also strongly associated with vascular remodeling - it causes hypertrophy and hyperplasia [31]. This activity is associated with numerous cellular signal transduction pathways through the angiotensin type 1 receptor. It intensifies proliferation, fibrosis and proinflammatory signals, which in turn causes progression of the disease [7]. Cousin and colleagues showed that the use of both angiotensin converting enzyme inhibitors and angiotensin type 1 receptor antagonists prevented hypertrophy of mesenteric artery walls in rats [32].

It is also worth emphasizing that activation of the angiotensin type 2 receptor induces the opposite effect as compared to the activation of the type 1 receptor for this protein, which makes it a potential target for the treatment [33]. Another protein associated with this system is angiotensin (1-7), which, when bound to the type 1 receptor, has the opposed activity to angiotensin II. In the literature there are also reports suggesting that angiotensin (1-7) prevents from vascular remodeling [34, 35].

\section{Endothelin 1}

Just like angiotensin II, endothelin 1 is an important protein regulating the vascular wall tension and participates in the remodeling observed in diseases such as HTN [36]. Under physiological conditions, binding of endothelin 1 to its A-type receptor (located mainly on smooth muscle cells of the vessel wall) causes vasoconstriction. Binding this molecule to the B-type receptor (which is located mainly on endothelial cells) causes vasodilatation by increasing the production of nitric oxide [37]. In disease states, we are dealing with an increase in the concentration of endothelin 1 and its receptors located on vessel wall smooth muscle cells [37]. Like angiotensin II, endo- 
thelin 1 causes the activation of numerous signaling pathways, resulting in increased proliferation, migration and fibrosis [31]. In addition, endothelin 1 may participate in vascular remodeling by regulating cell wall metalloproteinases and causing changes in extracellular matrix composition (including increasing the amount of collagen) [38, 39].

\section{Advanced glycation end products}

These compounds are proteins and fats that undergo glycation after exposure to carbohydrates. Their presence is associated with a number of complications, both micro- and macrovascular. They promote collagen accumulation and increase stiffness of tissues [40, 41]. Liu and colleagues in the HTN rat model showed that in this disease the increased concentration of both advanced glycation end products and receptors for them was observed. It was associated with endothelial dysfunction and vascular hypertrophy probably caused by increased smooth muscle vessel wall proliferation and increased deposition of collagen. This effect was caused by activation of the tissue renin-angiotensin-aldosterone system, increased concentration of reactive oxygen species and proinflammatory proteins [42].

\section{Inflammatory state}

Immune system cells, such as macrophages or T lymphocytes, play an important role in vascular remodeling and endothelial dysfunction $[43,44]$. The proinflammatory cytokines and interleukins produced by these cells contribute to remodeling [44]. Activation of NF-kB-transcription-factor-dependent pathways by pro-inflammatory substances is associated with augmentation of numerous pathways leading to vascular remodeling (including those involving angiotensin II, reactive oxygen species, endothelin 1 , or advanced glycation end products) [7]. In the literature, we also find reports that NF-kB directly activates the vessel wall smooth muscle proliferation and causes changes in their phenotype [7, 45]. Moreover, NF-kB also promotes the disease progression by increasing the expression of proinflammatory cytokines and adhesion molecules [46].

\section{Conclusions}

It seems that changes in the microcirculation occur at an earlier stage of the disease than changes in epicardial arteries. Further, detailed studies are necessary for better understanding the mechanisms of formation of abnormalities in the coronary microcirculation. This will probably allow for better control of cardiovascular complications occurring in the group of patients with HTN as well as with other cardiovascular diseases. Understanding these mechanisms is especially important in the group of patients in whom we do not observe significant lesions in coronary angiography, and who present with typical angina.

\section{References}

1. Mills KT, Bundy JD, Kelly TN, et al. Global Disparities of Hypertension Prevalence and Control: A Systematic Analysis of PopulationBased Studies From 90 Countries. Circulation. 2016; 134(6): 441-450, doi: 10.1161/CIRCULATIONAHA.115.018912, indexed in Pubmed: 27502908.

2. Tykarski A, Narkiewicz K, Gaciong Z, et al. Guidelines for the Management of Hypertension. Arterial Hypertens. 2015; 19(2): 53-83, doi: 10.5603/ah.2015.0010.

3. Lazzeroni D, Rimoldi O, Camici PG. From Left Ventricular Hypertrophy to Dysfunction and Failure. Circ J. 2016; 80(3): 555-564, doi: 10.1253/circj.CJ-16-0062, indexed in Pubmed: 26853555.

4. Díez J, González A, López B, et al. Mechanisms of disease: pathologic structural remodeling is more than adaptive hypertrophy in hypertensive heart disease. Nat Clin Pract Cardiovasc Med. 2005; 2(4): 209-216, doi: 10.1038/ncpcardio0158, indexed in Pubmed: 16265485 .

5. Moreno MU, Eiros R, Gavira JJ, et al. The Hypertensive Myocardium: From Microscopic Lesions to Clinical Complications and Outcomes. Med Clin North Am. 2017; 101(1): 43-52, doi: 10.1016/j.mcna.2016.08.002, indexed in Pubmed: 27884234.

6. Cramariuc D, Gerdts E. Epidemiology of left ventricular hypertrophy in hypertension: implications for the clinic. Expert Rev Cardiovasc Ther. 2016; 14(8): 915-926, doi: 10.1080/14779072.2016.1186542, indexed in Pubmed: 27159191.

7. Labazi H, Trask AJ. Coronary microvascular disease as an early culprit in the pathophysiology of diabetes and metabolic syndrome. Pharmacol Res. 2017; 123: 114-121, doi: 10.1016/j.phrs.2017.07.004, indexed in Pubmed: 28700893.

8. Matrougui K, Lévy B, Henrion D. Tissue angiotensin II and endothelin-1 modulate differently the response to flow in mesenteric resistance arteries of normotensive and spontaneously hypertensive rats. $\mathrm{Br}$ J Pharmacol. 2000; 130(3): 521-526, doi: 10.1038/sj.bjp.0703371.

9. Uematsu M, Ohara Y, Navas JP, et al. Regulation of endothelial cell nitric oxide synthase mRNA expression by shear stress. Am J Physiol. 1995; 269(6 Pt 1): C1371-C1378, doi: 10.1152/ ajpcell.1995.269.6.C1371, indexed in Pubmed: 8572165.

10. Malek A, Izumo S. Physiological fluid shear stress causes downregulation of endothelin-1 mRNA in bovine aortic endothelium. Am J Physiol. 1992; 263(2 Pt 1): C389-C396, doi: 10.1152/ ajpcell.1992.263.2.C389, indexed in Pubmed: 1514586.

11. Kassan M, Choi SK, Galán M, et al. Enhanced NF- $\kappa$ B activity impairs vascular function through PARP-1-, SP-1-, and COX-2dependent mechanisms in type 2 diabetes. Diabetes. 2013; 62(6): 2078-2087, doi: 10.2337/db12-1374, indexed in Pubmed: 23349490.

12. Wynne BM, Labazi H, Tostes RC, et al. Aorta from angiotensin II hypertensive mice exhibit preserved nitroxyl anion mediated relaxation responses. Pharmacol Res. 2012; 65(1): 41-47, doi: 10.1016/j. phrs.2011.07.002, indexed in Pubmed: 21767645.

13. Toque HA, Nunes KP, Yao L, et al. Akita spontaneously type 1 diabetic mice exhibit elevated vascular arginase and impaired 
vascular endothelial and nitrergic function. PLoS One. 2013; 8(8): e72277, doi: 10.1371/journal.pone.0072277, indexed in Pubmed: 23977269.

14. Kelm M, Strauer B. Coronary flow reserve measurements in hypertension. Med Clin North Am. 2004; 88(1): 99-113, doi: 10.1016/ s0025-7125(03)00119-6.

15. Duprez DA. Role of the renin-angiotensin-aldosterone system in vascular remodeling and inflammation: a clinical review. J Hypertens. 2006; 24(6): 983-991, doi: 10.1097/01. hih.0000226182.60321.69, indexed in Pubmed: 16685192

16. Schiffrin EL. Vascular remodeling in hypertension: mechanisms and treatment. Hypertension. 2012; 59(2): 367-374, doi: 10.1161/ HYPERTENSIONAHA.111.187021, indexed in Pubmed: 22203749.

17. Intengan H, Schiffrin E. Vascular Remodeling in Hypertension. Hypertension. 2001; 38(3): 581-587, doi: 10.1161/hy09t1.096249.

18. Camici PG, Crea F. Coronary microvascular dysfunction. N Engl J Med. 2007; 356(8): 830-840, doi: 10.1056/NEJMra061889, indexed in Pubmed: 17314342.

19. Spoladore R, Fisicaro A, Faccini A, et al. Coronary microvascular dysfunction in primary cardiomyopathies. Heart. 2014; 100(10): 806-813, doi: 10.1136/heartjnl-2013-304291, indexed in Pubmed: 23904360.

20. Rudic RD, Shesely EG, Maeda N, et al. Direct evidence for the importance of endothelium-derived nitric oxide in vascular remodeling. J Clin Invest. 1998; 101(4): 731-736, doi: 10.1172/JCI1699, indexed in Pubmed: 9466966.

21. Myers PR, Tanner MA. Vascular Endothelial Cell Regulation of Extracellular Matrix Collagen : Role of Nitric Oxide. Arterioscler Thromb Vasc Biol. 1998; 18(5): 717-722, doi: 10.1161/01. atv.18.5.717.

22. Hong Z, Reeves KJ, Sun Z, et al. Vascular smooth muscle cell stiffness and adhesion to collagen I modified by vasoactive agonists. PLoS One. 2015; 10(3): e0119533, doi: 10.1371/journal.pone.0119533, indexed in Pubmed: 25745858.

23. Numaguchi K, Egashira K, Takemoto M, et al. Chronic Inhibition of Nitric Oxide Synthesis Causes Coronary Microvascular Remodeling in Rats. Hypertension. 1995; 26(6): 957-962, doi: 10.1161/01. hyp.26.6.957.

24. Quintana-Villamandos B, Arnalich-Montiel A, Arribas S, et al. Early regression of coronary artery remodeling with esmolol and DDAH/ADMA pathway in hypertensive rats. Hypertens Res. 2016; 39(10): 692-700, doi: 10.1038/hr.2016.57, indexed in Pubmed: 27250567.

25. Quintana-Villamandos B, González MC, Delgado-Martos MJ, et al. Short-term esmolol attenuates remodeling of the thoracic aorta in hypertensive rats by decreasing concentrations of ADMA down-regulated by oxidative stress. Eur J Pharmacol. 2016; 791: 502-509, doi: 10.1016/j.ejphar.2016.09.020, indexed in Pubmed: 27639298.

26. Toque HA, Nunes KP, Rojas M, et al. Arginase 1 mediates increased blood pressure and contributes to vascular endothelial dysfunction in deoxycorticosterone acetate-salt hypertension. Front Immunol. 2013; 4: 219, doi: 10.3389/fimmu.2013.00219, indexed in Pubmed: 23908657.

27. Virdis A, Neves MF, Amiri F, et al. Role of $\mathrm{NAD}(\mathrm{P}) \mathrm{H}$ oxidase on vascular alterations in angiotensin II-infused mice. J Hypertens. 2004; 22(3): 535-542, indexed in Pubmed: 15076159.

28. Cho YE, Basu A, Dai A, et al. Coronary endothelial dysfunction and mitochondrial reactive oxygen species in type 2 diabetic mice. Am J Physiol Cell Physiol. 2013; 305(10): C1033-C1040, doi: 10.1152/ ajpcell.00234.2013, indexed in Pubmed: 23986204.

29. Wang C, Luo Z, Kohan D, et al. Thromboxane prostanoid receptors enhance contractions, endothelin-1, and oxidative stress in microvessels from mice with chronic kidney disease. Hypertension. 2015; 65(5): 1055-1063, doi: 10.1161/HYPERTENSIONAHA.115.05244, indexed in Pubmed: 25733239.

30. Staiculescu MC, Foote $\mathrm{C}$, Meininger GA, et al. The role of reactive oxygen species in microvascular remodeling. Int J Mol Sci. 2014; 15(12): 23792-23835, doi: 10.3390/ijms151223792, indexed in Pubmed: 25535075.
31. Wynne BM, Chiao CW, Webb RC. Vascular Smooth Muscle Cell Signaling Mechanisms for Contraction to Angiotensin II and Endothelin-1. J Am Soc Hypertens. 2009; 3(2): 84-95, doi: 10.1016/j. jash.2008.09.002, indexed in Pubmed: 20161229.

32. Cousin M, Custaud MA, Baron-Menguy C, et al. Role of angiotensin II in the remodeling induced by a chronic increase in flow in rat mesenteric resistance arteries. Hypertension. 2010; 55(1): 109-115, doi: 10.1161/HYPERTENSIONAHA.108.127456, indexed in Pubmed: 19948989.

33. Paulis L, Becker STR, Lucht K, et al. Direct angiotensin II type 2 receptor stimulation in $\mathrm{N} \omega$-nitro-L-arginine-methyl ester-induced hypertension: the effect on pulse wave velocity and aortic remodeling. Hypertension. 2012; 59(2): 485-492, doi: 10.1161/HYPERTENSIONAHA.111.185496, indexed in Pubmed: 22215717.

34. Santos RAS, Ferreira AJ, Verano-Braga T, et al. Angiotensin-converting enzyme 2 , angiotensin-(1-7) and Mas: new players of the renin-angiotensin system. J Endocrinol. 2013; 216(2): R1-R17, doi: 10.1530/JOE-12-0341, indexed in Pubmed: 23092879.

35. Zhang Z, Chen L, Zhong J, et al. ACE2/Ang-(1-7) signaling and vascular remodeling. Sci China Life Sci. 2014; 57(8): 802-808, doi: 10.1007/s11427-014-4693-3, indexed in Pubmed: 25104453.

36. Sachidanandam K, Hutchinson JR, Elgebaly MM, et al. Glycemic control prevents microvascular remodeling and increased tone in type 2 diabetes: link to endothelin-1. Am J Physiol Regul Integr Comp Physiol. 2009; 296(4): R952-R959, doi: 10.1152/ ajpregu.90537.2008, indexed in Pubmed: 19176890.

37. Böhm F, Pernow J. The importance of endothelin-1 for vascular dysfunction in cardiovascular disease. Cardiovasc Res. 2007; 76(1): 8-18, doi: 10.1016/j.cardiores.2007.06.004, indexed in Pubmed: 17617392.

38. Pu Q, Neves MF, Virdis A, et al. Endothelin antagonism on aldosterone-induced oxidative stress and vascular remodeling. Hypertension. 2003; 42(1): 49-55, doi: 10.1161/01.HYP.0000078357.92682. EC, indexed in Pubmed: 12782645.

39. Sachidanandam K, Portik-Dobos V, Kelly-Cobbs AI, et al. Dual endothelin receptor antagonism prevents remodeling of resistance arteries in diabetes. Can J Physiol Pharmacol. 2010; 88(6): 616-621, doi: 10.1139/Y10-034, indexed in Pubmed: 20628426.

40. Schmidt AM, Yan SD, Wautier JL, et al. Activation of Receptor for Advanced Glycation End Products: A Mechanism for Chronic Vascular Dysfunction in Diabetic Vasculopathy and Atherosclerosis. Circ Res. 1999; 84(5): 489-497, doi: 10.1161/01. res.84.5.489.

41. Aronson D. Cross-linking of glycated collagen in the pathogenesis of arterial and myocardial stiffening of aging and diabetes. J Hypertens. 2003; 21(1): 3-12, doi: 10.1097/01.hjh.0000042892.24999.92, indexed in Pubmed: 12544424.

42. Liu Yu, Yu M, Zhang Le, et al. Soluble receptor for advanced glycation end products mitigates vascular dysfunction in spontaneously hypertensive rats. Mol Cell Biochem. 2016; 419(1-2): 165-176, doi: 10.1007/s11010-016-2763-5, indexed in Pubmed: 27426491.

43. De Ciuceis C, Amiri F, Brassard P, et al. Reduced vascular remodeling, endothelial dysfunction, and oxidative stress in resistance arteries of angiotensin II-infused macrophage colony-stimulating factordeficient mice: evidence for a role in inflammation in angiotensininduced vascular injury. Arterioscler Thromb Vasc Biol. 2005; 25(10): 2106-2113, doi: 10.1161/01.ATV.0000181743.28028.57, indexed in Pubmed: 16100037.

44. Guzik TJ, Hoch NE, Brown KA, et al. Role of the T cell in the genesis of angiotensin II induced hypertension and vascular dysfunction. J Exp Med. 2007; 204(10): 2449-2460, doi: 10.1084/ jem.20070657, indexed in Pubmed: 17875676.

45. Ogawa A, Firth AL, Yao W, et al. Prednisolone inhibits PDGFinduced nuclear translocation of NF-kappaB in human pulmonary artery smooth muscle cells. Am J Physiol Lung Cell Mol Physiol. 2008; 295(4): L648-L657, doi: 10.1152/ajplung.90245.2008, indexed in Pubmed: 18708631.

46. Hoeth M, Hofer-Warbinek R, Schmid JA. The Transcription Factor NF- B and the Regulation of Vascular Cell Function. Arterioscler Thromb Vasc Biol. 2000; 20(11): e83-e88, doi: 10.1161/01. atv.20.11.e83. 